\title{
Variation in Medicaid Coverage for Hematopoietic Cell Transplantation
}

\author{
By Jaime M. Preussler, MS, Stephanie H. Farnia, MPH, Ellen M. Denzen, MS, \\ and Navneet S. Majhail, MD, MS \\ National Marrow Donor Program; and Center for International Blood and Marrow Transplant Research, Minneapolis, MN
}

\begin{abstract}
Purpose: Variation in Medicaid policies among states may lead to differences in coverage for complex treatments. This article uses hematopoietic cell transplantation (HCT), an established treatment for patients with hematologic cancers, as a case study to highlight state variation in Medicaid coverage of complex oncology treatments.
\end{abstract}

Methods: Information on HCT coverage benefits for 2012 was collected from state Medicaid Web sites and was compared with recommended HCT benefits developed by multiple stakeholders. Coverage was reviewed for five categories: one, transplantation procedure; two, donor search; three, prescriptions; four, clinical trials; and five, patient food, lodging, and transportation.

\section{Introduction}

The federally created Medicaid program currently provides health care coverage to approximately 60 million people in the United States. Each state establishes and administers the Medicaid program within the state and determines the scope of services it provides within federal guidelines. Although the federal government mandates that certain services be covered by every state plan, states decide on the amount, duration, and scope of those services. Furthermore, states can decide whether to cover other services defined by the federal government as optional benefits. Regardless of whether a service is designated as mandatory or optional, procedure details are generally not specified, which leads to wide variation in coverage provided by states. ${ }^{1}$

There is a possibility that state policy variations may lead to gaps in Medicaid coverage for complex treatments and procedures in oncology and, as a result, may affect access to care and patient outcomes. To further examine this issue, we evaluated variation in Medicaid coverage for hematopoietic cell transplantation (HCT), an optional benefit under Medicaid. HCT is an example of a nondrug oncology service for which there is no specific coverage guidance.

HCT is primarily used for the treatment of blood cancers and other hematologic diseases. It can be performed using a patient's own hematopoietic stem cells (autologous HCT) or using hematopoietic stem cells from a living donor (allogeneic HCT). For allogeneic transplantation, the donor must be immunologically similar (matched at multiple HLA loci) and can be a related (generally a sibling) donor or a matched unrelated
Coverage was coded on a three-point scale for each category for each state. States were ranked by the number of variables for which they met recommended benefits criteria (maximum rank score, 5).

Results: Detailed information on Medicaid coverage was available for 47 states. No state provided the recommended coverage benefits in all five categories. Prescription coverage most often met the recommended criteria, whereas only a small number of states provided clinical trial coverage for HCT. There was substantial variation in Medicaid coverage for HCT by state.

Conclusion: Findings highlight substantial variation in Medicaid coverage for HCT by state, which may increase disparities in access for already medically underserved populations.

donor. Approximately 20,000 HCTs are performed in the United States annually, ${ }^{4}$ and that number is expected to increase with technologic and care improvements, improved outcomes, and the introduction of newer indications and donor sources. 5,6 At the same time, many patients, especially from underserved populations, do not have sufficient access to this

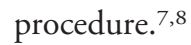

HCT is a highly specialized and expensive procedure, and transplantation centers frequently will not perform HCT for uninsured or underinsured patients. Adequate coverage for several critical components, in addition to the transplantation procedure itself, is required for successful outcomes. There are costs associated with the collection and processing of the hematopoietic stem-cell graft and, in the case of allogeneic HCT, with HLA typing and identification of a suitable donor. Also, patients may require many expensive medications (eg, antimicrobials, immunosuppressants) and frequently have to relocate to be near the transplantation center, incurring substantial expenses and facing potentially negative outcomes if not covered or if unaffordable. Patients also need comprehensive post-transplantation care over months to years to monitor the transplanted graft, complications, and potential disease relapse.

A multidisciplinary group of stakeholders, including transplantation physicians, large national health insurance companies, and transplantation networks and administrators from hospitals with HCT programs, has proposed recommendations for designing an effective benefits plan (ie, recommended benefits) for HCT (Table 1). ${ }^{9}$ Recommended benefits are suggested for various components of HCT, including donor search, cell 
Table 1. Recommendations for Designing Effective Benefits Plan for HCT

\begin{tabular}{|c|c|c|c|c|}
\hline $\begin{array}{l}\text { Transplantation } \\
\text { Coverage }\end{array}$ & $\begin{array}{l}\text { Donor Search-Cell } \\
\text { Procurement }\end{array}$ & Medications & Clinical Trials & Travel and Lodging \\
\hline $\begin{array}{l}\text { Coverage of HCT and } \\
\text { subsequent } \\
\text { therapeutic } \\
\text { infusions for all } \\
\text { medically } \\
\text { necessary } \\
\text { indications }\end{array}$ & $\begin{array}{l}\text { Unrelated donor: full coverage } \\
\text { of tissue typing/testing } \\
\text { through NMDP or other } \\
\text { approved registry; full } \\
\text { coverage of cell } \\
\text { procurement }\end{array}$ & $\begin{array}{l}\text { Coverage of all necessary medications } \\
\text { throughout HCT process, including } \\
\text { post-transplantation medications, } \\
\text { without copayment or coinsurance }\end{array}$ & $\begin{array}{l}\text { Coverage of clinical trials appropriate } \\
\text { to patient stage, indication, and } \\
\text { clinical condition }\end{array}$ & $\begin{array}{l}\text { Full coverage of travel and } \\
\text { lodging costs for } \\
\text { member and caregiver } \\
\text { for transplantation visit, } \\
\text { in addition to necessary } \\
\text { pre-and post- } \\
\text { transplantation } \\
\text { evaluations }\end{array}$ \\
\hline \multirow[t]{3}{*}{$\begin{array}{l}\text { No limit on inpatient } \\
\text { stays or outpatient } \\
\text { visits }\end{array}$} & $\begin{array}{l}\text { Related donor: full coverage } \\
\text { of tissue typing; full } \\
\text { coverage of cell } \\
\text { procurement, including } \\
\text { travel and lodging for } \\
\text { selected donor }\end{array}$ & & $\begin{array}{l}\text { Minimum: coverage of routine care } \\
\text { for patients in clinical trials, per } \\
\text { requirements in Affordable Care } \\
\text { Act }\end{array}$ & \\
\hline & $\begin{array}{l}\text { Autologous collection: full } \\
\text { coverage of preparation, } \\
\text { harvest, and storage of } \\
\text { cells }\end{array}$ & & & $\begin{array}{l}\text { Cover costs for second } \\
\text { caregiver if patient is } \\
\text { age }<18 \text { years }\end{array}$ \\
\hline & $\begin{array}{l}\text { No limit on typing/testing } \\
\text { costs if potential donors are } \\
\text { in covered categories }\end{array}$ & & & \\
\hline
\end{tabular}

NOTE. Data adapted. 9

Abbreviations: HCT, hematopoietic cell transplantation; NMDP, National Marrow Donor Program.

procurement, cell infusion and HCT, travel and lodging assistance for patients, inpatient and outpatient lengths of stay, medications, and coverage for clinical trials. A rationale for each recommendation and relevant administrative guidance are also provided.

According to the Nationwide Inpatient Sample, which captures hospitalizations in the United States, $16 \%$ of all HCTs were covered by Medicaid in 2010. ${ }^{10}$ However, HCT coverage varies widely among state Medicaid programs, and each state has the discretion to choose whether to cover HCTs, because HCT services are not mandatory services. When a state elects to cover transplantation services, federal financial participation is limited to only those transplantation procedures with written standards of coverage described in the state Medicaid plan. ${ }^{11}$ States are free to define for which diseases HCT will be covered and are authorized to impose limits on HCT services and place restrictions on the facilities and practitioners performing transplantations. One exception is the Early and Periodic Screening Diagnostic and Treatment Program for individuals age $<21$ years, which covers all nonexperimental transplantations, whether or not the particular procedure is covered by the state Medicaid plan. ${ }^{11}$

\section{Methods}

To characterize variation in coverage for HCT among state Medicaid programs, we reviewed Web sites for state Medicaid plans and administrative guidelines for the calendar year 2012. Review was limited to state plans rather than specific managed care plans. When states did not have information online, state Medicaid offices were contacted by e-mail when available or by telephone. If information was still unavailable, hospitals with HCT programs were contacted for information regarding Medicaid coverage in their state. To ensure consistency in data collection, information was obtained by one investigator (J.M.P.) and captured using a uniform template for all states. If the initial contact was not successful, additional contact by telephone and/or e-mail was made to the state Medicaid offices.

Benefits identified for each state were compared with the recommended benefits for HCT. The recommended benefits were designed with the commercial payer in mind and include specific dollar limits per benefit. Because Medicaid reimbursement is different from that of commercial insurers, these dollar limits were not included in the analysis. Categories where coverage information was not available despite a thorough search for information were classified as not available.

Data were coded on a three-point scale for each state based on whether coverage met recommended benefits criteria (score of 2), provided for some but not all recommended benefits (score of 1), or did not provide any of the recommended benefits (score of 0 ) for the following five categories: one, HCT procedure and disease indications; two, donor search; three, medications; four, clinical trials; and five, patient food, lodging, and transportation. Two reviewers (J.M.P., S.H.F.) independently coded information for each state, and differences were resolved by consensus with a third reviewer (N.S.M.). Because state plan descriptions varied in level of detail, attention was given to whether a benefit existed at all and, if so, whether it was sufficient enough for a patient to actually undergo HCT. For each state, we summed the number of categories for which recommended benefits criteria were met.

\section{Results}

Among the 47 states for which data were available, no state provided recommended benefits in all five categories, and only four states met at least four of the five categories (Table 2; Fig 1). Fifteen states did not provide any information in at least one of the categories. The clinical trials category was the most common category for which coverage was not provided; only two states met the recommended benefits criteria for HCT clinical trial coverage. On evaluating coverage for the remaining four 
Table 2. Medicaid Coverage for HCT by State

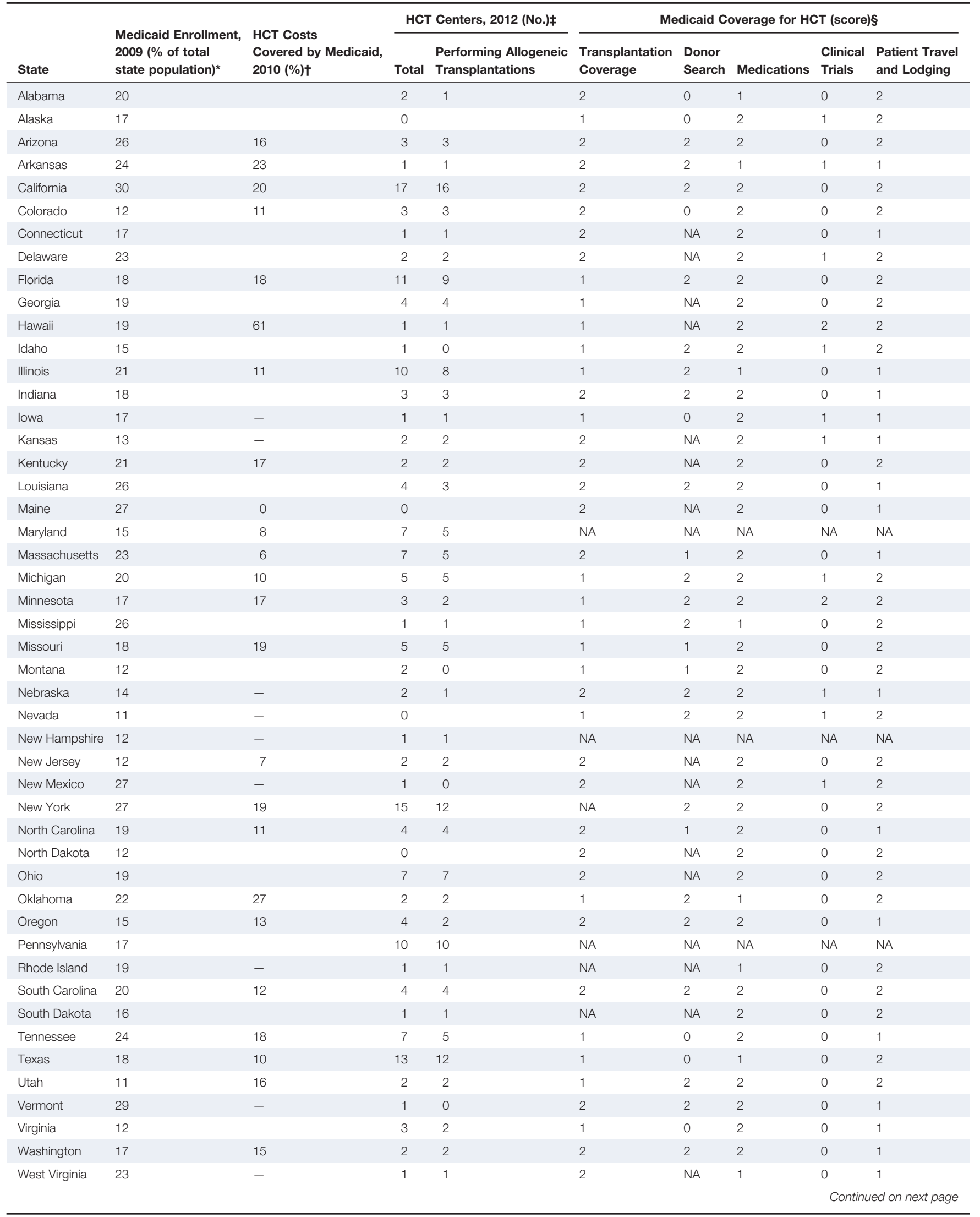


Table 2. (Continued)

\begin{tabular}{|c|c|c|c|c|c|c|c|c|c|}
\hline State & $\begin{array}{l}\text { Medicaid Enrollment, } \\
2009(\% \text { of total } \\
\text { state population) }\end{array}$ & $\begin{array}{l}\text { HCT Costs } \\
\text { Covered by Medicaid, } \\
2010(\%) \dagger\end{array}$ & \multicolumn{2}{|c|}{ НCT Centers, 2012 (No.)‡ } & \multicolumn{5}{|c|}{ Medicaid Coverage for HCT (score)§ } \\
\hline Wyoming & 15 & 0 & 0 & & 2 & 0 & 2 & 0 & 2 \\
\hline
\end{tabular}

Abbreviations: HCT, hematopoietic cell transplantation; NA, not available.

* Data adapted. ${ }^{12}$

† Data adapted. ${ }^{13}$ Statistics for some states not available (indicated by blank space); data suppressed for states with $\leq 10$ discharges or < two hospitals for procedure/ diagnosis of interest (indicated by - ).

$\neq$ Data adapted. ${ }^{14}$

$\S$ Coverage categories: coverage met criteria, score of 2; met some but not all criteria, score of 1 ; or did not meet any criteria, score of 0 .

categories (excluding coverage for clinical trials), most states still did not meet the coverage criteria. Only four of the 47 states provided recommended benefits coverage for all four categories; 21 provided coverage for three categories, and 22 provided coverage for $\leq$ two categories.

Among states that did not fully meet the recommended benefits, some common themes were identified that have the potential to limit access to HCT among Medicaid patients who undergo transplantation. In some states, standard established indications for HCT were not covered, coverage was limited to a dollar amount insufficient to cover the cost of HCT, or the number of inpatient days allowed annually was limited. Coverage for donor search varied widely among states, with eight states not providing coverage at all, and 20 states providing the recommended benefits. Most states $(\mathrm{n}=39)$ provided the recommended prescription benefits. However, the majority of states $(n=35)$ did not cover clinical trials. Although many patients have to relocate to be closer to their transplantation center, and it is not unusual for patients to stay nearby for $\geq 3$ months post-transplantation, only 29 states provided the recommended benefits for patient lodging and transportation coverage.

\section{Discussion}

We found that although all states provide coverage for HCT through their Medicaid programs, there is considerable vari- ation in the amount and type of coverage provided, and frequently the coverage may be inadequate for successful transplantation. Examples of coverage restrictions that can serve as barriers to HCT access included lack of coverage for standard indications of transplantation, limitations on the number of inpatient days allowed per annum, and absence of coverage for searching for a donor. Variation in individual state Medicaid coverage guidelines is inherent in the federalstate design of the Medicaid program; however, gaps in coverage across states have the potential to lead to health care disparities in access and outcome. With the expansion of Medicaid under the Patient Protection and Affordable Care Act, variations in Medicaid policies have the potential to add to disparities in care. It would benefit patients to have a standard benefit set for complex oncology services such as HCT. This would ensure adequate coverage is provided for Medicaid patients who need such procedures, regardless of state of residence.

Although our analysis focused on HCT, which is a unique cancer treatment, our findings can be extrapolated to other areas in oncology. Most Medicaid programs clearly define coverage guidelines for common cancers (eg, breast and colon cancers). However, coverage details for other cancers may not be specific, and variation in coverage may contribute to disparities

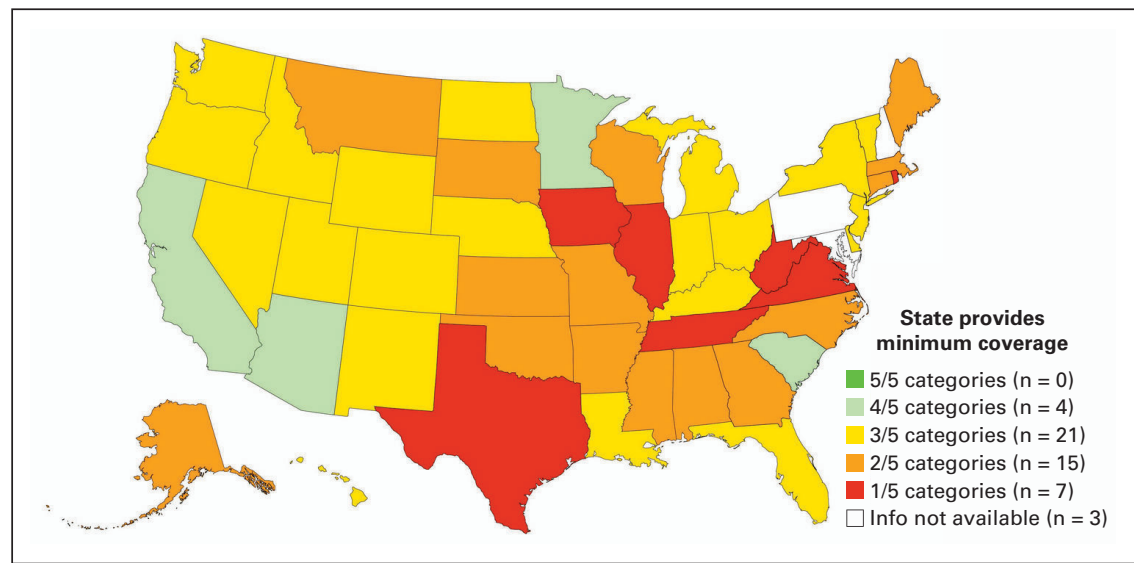

Figure 1. Medicaid coverage for hematopoietic cell transplantation by state. Each state was coded on whether it provided recommended benefits for transplantation on a three-point scale (coverage met criteria, score of 2; met some but not all criteria, score of 1; or did not meet any criteria, score of 0) for the following five categories: (1) transplantation procedure and disease indications; (2) donor search; (3) medications; (4) clinical trials; and (5) patient food, lodging, and transportation. States were ranked by the number of categories for which they met recommended benefits criteria (maximum score, 5). 
in cancer care, especially if treatment requires a combination of several specialists and modalities.

There were five states that did not have a transplantation center; this alone can significantly limit access to HCT, because other states are not required to accept out-of-state Medicaid patients. Provision of out-of-state benefits and acceptance of them for high-cost services like HCT is an area for further research. We used publically available information to determine Medicaid coverage for HCT. We were able to obtain detailed information for most states; however, publically available information may not provide comprehensive details on state Medicaid plans. Additionally, what is written in the plans may not be how transplantation centers or patients experience coverage. More research is needed to better understand gaps in Medicaid coverage for HCT. Future research will also need to focus on variation in HCT benefits by the proportion of the state population insured by Medicaid, as well as quantitatively examine whether variations in coverage policy do indeed result in access barriers or poorer outcomes. Finally, our findings also need to be validated by studies investigating patient- and transplantation center-level experience and outcomes.

During our study, we learned that identifying Medicaid benefits for HCT can be challenging. Although information is publically available, it is not easily accessible. Given that Medicaid beneficiaries typically belong to medically underserved populations, presentation of benefit and coverage details in a more readily accessible format would assist patients and their caregivers in better understanding their options. At the same time, we do acknowledge that transplantation centers likely have resources such as financial coordinators who can assist patients in understanding their coverage options.

Some limitations of our analysis must be considered. We did not consider managed care plan details in our analysis. Medicaid rules and regulations are frequently updated by states, and hence, our study represents a cross-sectional perspective on Medicaid coverage for HCT. Some states and transplantation centers may have alternative funding sources to help patients with Medicaid cover the cost of transplantation, which we could not consider in our study. One of the main categories for

\section{References}

1. Medicaid and CHIP Payment and Access Commission: Report to the Congress on Medicaid and CHIP. https://docs.google.com/viewer?a=v\&pid=sites\&srcid= bWFjcGFjLmdvdnxtYWNwYWN8Z3g6NTZmYjJ1ZDcwMTQZMDcOMA

2. Reference deleted

3. Reference deleted

4. Pasquini MC, Wang Z, Horowitz MM, et al: 2010 report from the Center for International Blood and Marrow Transplant Research (CIBMTR): Current uses and outcomes of hematopoietic cell transplants for blood and bone marrow disorders. Clin Transpl 2010:87-105, 2010

5. Gratwohl A, Baldomero H, Aljurf M, et al: Hematopoietic stem cell transplantation: A global perspective. JAMA 303:1617-1624, 2010

6. Majhail NS, Murphy EA, Omondi NA, et al: Allogeneic transplant physician and center capacity in the United States. Biol Blood Marrow Transplant 17:956-961, 2011

7. Majhail NS, Nayyar S, Santibañez ME, et al: Racial disparities in hematopoietic cell transplantation in the United States. Bone Marrow Transplant 47:1385-1390, 2012 which we were not able to obtain sufficient detail was coverage for donor search (missing for 15 of 47 states included in our analysis). However, none of these 15 states would have met criteria for all recommended benefits even if they provided minimum coverage for donor search. At the same time, ability to search for donors is a critical component of HCT, and clearer guidance on coverage for this part of HCT would be helpful for patients and transplantation centers.

In summary, there exists considerable variation in coverage for HCT through individual state Medicaid programs. Advocacy for transplantation as part of state benefit sets and federal guidance on a recommended benefit set that states can consider would be beneficial to ensure adequate coverage is provided for Medicaid patients who need such procedures, regardless of state of residence.

\section{Acknowledgment}

We thank Michael Boo, JD, chief strategy officer, and Elizabeth Murphy, $E d D, R N$, vice president of patient and health professional services, of the National Marrow Donor Program, and Sharon Long, PhD, of the Urban Institute, for their review of our manuscript.

\section{Authors' Disclosures of Potential Conflicts of Interest}

The authors indicated no potential conflicts of interest.

\section{Author Contributions \\ Conception and design: All authors}

Collection and assembly of data: Jaime M. Preussler, Stephanie H. Farnia, Navneet S. Majhail

Data analysis and interpretation: All authors

Manuscript writing: All authors

Final approval of manuscript: All authors

Corresponding author: Navneet S. Majhail, MD, MS, Medical Director, Health Services Research, National Marrow Donor Program, 3001 Broadway St NE, Suite 100, Minneapolis, MN 55413; e-mail: nmajhail@nmdp.org.

DOI: 10.1200/JOP.2013.001155; published online ahead of print at jop.ascopubs.org on April 8, 2014.

8. Majhail NS, Omondi NA, Denzen E, et al: Access to hematopoietic cell transplantation in the United States. Biol. Blood Marrow Transplant 16:1070-1075, 2010

9. Be the Match: Payor resources. payor.bethematchclinical.org

10. Agency for Healthcare Research and Quality: HCUPnet: Payer path: National, regional and state estimates on hospital use by payer. http://hcupnet.ahrq. gov/HCUPnet.jsp

11. Reference deleted

12. Kaiser Family Foundation: State health facts. http://www.statehealthfacts. org/comparecat.jsp?cat $=4 \&$ rgn $=6 \&$ rgn $=1$

13. Agency for Healthcare Research and Quality: HCUPnet: ICD9 procedure codes for hematopoietic cell transplantation (41.00-41.09). http://hcupnet.ahrq. gov/

14. Center for International Blood and Marrow Transplant Research. www. cibmtr.org 